\title{
The optimal migration duration and activity choice after re-migration
}

\author{
Christian Dustmann $^{\mathrm{a}, *}$, Oliver Kirchkamp ${ }^{\mathrm{b}}$ \\ ${ }^{\mathrm{a}}$ Department of Economics, University College London, Gower Street, London WC IE 6BT, UK \\ ${ }^{\mathrm{b}} \mathrm{SFB}$ 504, D-68131 Mannheim University, Germany
}

Received 1 August 1999; accepted 1 June 2001

\begin{abstract}
If migrants return to their origin countries, two questions arise which are of immediate economic interest for both immigration and emigration country: what determines their optimal migration duration, and what are the activities migrants choose after a return. Little research has been devoted to these two issues. This paper utilises a unique survey data set which records activities of returned migrants. We first illustrate the activities of immigrants after returning. We show that more than half of the returning migrants are economically active after return, and most of them engage in entrepreneurial activities. We then develop a model where migrants decide simultaneously about the optimal migration duration, and their after-return activities. Guided by this model, we specify and estimate an empirical model, where the after-return activity, and the optimal migration duration are simultaneously chosen. (C) 2002 Elsevier Science B.V. All rights reserved.
\end{abstract}

Keywords: Life cycle models; International migration; Qualitative choice models

\section{Introduction}

Much research in economics is devoted to studying whether migration is economically beneficial for the immigration country. There are numerous papers which investigate the economic performance of immigrants in the host economies (e.g. Chiswick, 1978; Borjas, 1987; Galor and Stark, 1991), and their contributions to the welfare systems of the host countries (see, for instance, Borjas, 1994). The beneficial aspects migration may have for

\footnotetext{
* Corresponding author. Tel.: +44-207-387-7860; fax: +44-207-916-2775.

E-mail addresses: c.dustmann@ucl.ac.uk (C. Dustmann), oliver@kirchkamp.de (O. Kirchkamp).
} 
the home country economies has received less attention. But migration can also be welfare-enhancing for those individuals who stay behind. One channel to re-distribute the welfare gains of migrants to non-migrants who remain in the source country are remittances. Savings and remittances of migrants may provide badly needed capital inflows, help to overcome capital constraints, and act as development support for the migrant's home region. ${ }^{1}$ Research which investigates remittance behaviour of immigrants includes Lucas and Stark (1985) and Funkhouser (1992).

If migrations are temporary, there is an additional way the source country can benefit. Returning migrants may bring skills and capital to the home economy, and contribute to economic prosperity in the home country by their after-return economic activities. Both human and physical capital may be important to promote economic growth in the emigration country. In fact, returning migrants have in the past been identified by the political leadership of emigration countries as one channel of acquiring expertise. ${ }^{2}$

Savings of returning migrants may be used to acquire durable consumption goods, and to allow for a steady income after returning. Savings may also be put into productive use. Entrepreneurial activities of returning migrants may contribute to wealth generation, and create jobs. Capital constraints in the home economy may hinder individuals to start an enterprise, and migration may be one way to overcome these constraints (see Mesnard (2000) on the relationship between migration and credit market rationing). Migration is then part of a life cycle plan to accumulate capital for self-employment activities, or for pure leisure activities after returning.

In this context, it is of interest to understand how migrants decide about re-migration and the economic activities they pursue after returning. Furthermore, what determines the optimal length of migration if migrants return, and how does this decision interact with future activity choices. So far, theoretical models which investigate the determinants for return migration and the optimal migration duration (as in Dustmann, 1995, 1997, 2001; Stark et al., 1997) are based on the assumption that there is only one activity the migrant pursues after a return. However, if there is a range of activities the migrant may choose after returning, and if migration duration and after-migration activity are jointly chosen, then the optimal migration duration may differ across activities. Furthermore, the way economic variables (like wages in the home- and host region) are related to optimal migration durations may likewise differ, according to the envisaged after-return activity.

In this paper, we study optimal migration durations and activity choices after return migration. We use data from a unique survey data set of Turkish immigrants to Germany who returned to Turkey in 1984, and who were subsequently interviewed in their home country in 1986 and 1988 . We show that about half of the returning population of

\footnotetext{
1 Robinson (1986) reports hat remittances from Pakistanis to the Middle East finance some 86\% of Pakistan's trade deficit. Hiemenz and Schatz (1979) report that in 1973, transfers of earnings of Turkish and Yugoslav workers in Germany amounted to more than twice the total foreign exchange obtained through exports of goods from those countries to Germany.

2 For instance, Mehrldnder (1980) reports that labour migration from Europe's periphery countries to Northern Europe in the 1950s-1970s was regarded by emigration countries as a means to acquire expertise and knowledge, which is needed for the development of their own industries.
} 
immigrants becomes active as an entrepreneur after return, and that the capital for starting off a business stems from savings and capital acquired abroad.

We then build a simple model for the optimal migration duration, and after-return activities. Other than in the before-mentioned previous studies, where migrants are assumed to continue working as salaried workers after return, in our model the migrant chooses to become self-employed, salaried employed, or to retire from the labour force. These choices are met jointly with the decision about the amount of savings to be accumulated, and the optimal migration duration. Accordingly, the optimal migration duration is chosen in conjunction with the optimal after-migration activity. This model produces a number of interesting insights. We find that economic variables affect the optimal migration duration differently, according to which after-return activity is chosen. Furthermore, an increase in the host country wage does not necessarily lead to increased migration durations - on the contrary, it may lead to a decrease in the migration duration. Also, our analysis adds a further motive for a return migration: a high return to selfemployment activities in the migrant's home economy.

We then specify an empirical model of activity choice and optimal migration duration, which is motivated by our theoretical model. We estimate the activity choice as a multinomial choice model, where the future activity is simultaneously determined with the optimal migration duration in each of the three regimes. We allow explanatory variables to affect migration durations differently in the different regimes, and we test the restrictions implied by models which only allow for one activity after return. Our empirical model is compatible with the hypothesis that higher earnings in the host country, in conjunction with a planned entrepreneurship after return, reduce migration durations.

The paper is structured as follows. The next section describes the circumstances leading to the migration and return migration to which our data refer. Furthermore, based on our data, we discuss some interesting aspects of activities of returned migrants. Section 3 presents a simple structural model on re-migration and activity choice, and the optimal migration duration. Section 4 develops the empirical model, and discusses the results of empirical estimations. Finally, Section 5 concludes.

\section{Background and data}

Between the mid-1950s and 1973, the strong economic development in Northern Europe and the resulting demand for labour led to a large inflow of migrants mainly from the periphery countries of Europe, but also from Turkey, North Africa, South America and Asia, into central Europe. The main receiving countries were Belgium, France, Germany, the Netherlands, Switzerland, and the Scandinavian countries. This movement came to a halt in 1973/1974, the turning point of the rapid economic development in Northern Europe, when countries stopped active recruitment policies and/or put severe restrictions on further labour immigration.

In Germany, the strong upward swing of the economy after 1955, which was accompanied by a sharp fall in the unemployment rate and an increase in labour demand, created a large wave of immigrants from Southern European countries and Turkey. The percentage of foreign born workers employed in West Germany increased from $0.6 \%$ in 
1957 to $5.5 \%$ in 1965 to $11.2 \%$ in 1973 , and slightly declined thereafter. The stock of the foreign population increased from 700,000 in 1961 to 3.96 million in 1973.

Bilateral recruitment agreements between Germany and Italy, Spain, Greece, Turkey, Portugal and Yugoslavia in the 1950s and 1960s reduced the migrants' cost of migration considerably: workers entered Germany with a 1 year working contract, they could not be dismissed during the first year, travel costs were re-imbursed, and employers had to provide accommodation (Mehrldnder, 1980, p. 82). In 1973, as a reaction to the first oil crisis, which marked the turning point of the strong upward movement of the German economy, active recruitment of foreign labour came to a standstill. After 1973, many families and dependents of workers immigrated to Germany.

The migrant population which we analyse in this paper stems from this movement. In the early 1980s, growing unemployment rates, and a strong economic downturn, led countries like Belgium, France, Germany and the Netherlands to adopt policies which were aimed to encourage immigrant workers to return. In 1984, Germany initiated a repatriation scheme, mainly aimed at migrants from Turkey. The scheme foresaw financial incentives for immigrants who were willing to return to their home country (see Hönekopp, 1987 for details). The German Institut für Arbeitsmarks-und Berufsforschung (IAB) initiated a survey among those immigrants who applied for return assistance. A random sample of 1200 individuals who wished to return, and who applied for return assistance, was interviewed before leaving Germany in 1984. In 1986 and in 1988, 800 of these individuals were traced and re-interviewed in Turkey. The 1988 survey contains detailed information on migrants' economic activities.

The survey includes questions on a variety of economic and social issues. In the following analysis, we combine information provided in the three survey years, which restricts our sample to individuals who are responding in all the three waves. We further exclude females and individuals who were younger than 18 at emigration, since they are unlikely to have made an independent emigration choice. Our final sample includes 646 individuals.

Table 1 reports summary statistics on the three labour market states Non Participation, Salaried Worker, and Self Employed, for the survey year 1988. The category Salaried Worker includes individuals who are working, or who report that they are actively looking for work.

Interestingly, half of the migrants are engaged in some sort of entrepreneurial activity 4 years after return. About $43 \%$ do not participate in the labour market, and only about $6 \%$

Table 1

Labour force status

\begin{tabular}{lrr}
\hline & Number & Percentage \\
\hline Not participating & 276 & 42.72 \\
Salaried worker & 40 & 6.20 \\
Self-employed & 330 & 51.10 \\
All & 646 & 100 \\
Wave 1988 & & \\
\hline
\end{tabular}


Table 2

Sector choice, entrepreneurs

\begin{tabular}{lcc}
\hline & Number & Percentage \\
\hline Agriculture & 128 & 39.14 \\
Trade & 97 & 29.66 \\
Craft & 43 & 13.15 \\
Services & 59 & 18.04 \\
All & 327 & 100.00 \\
& & \\
Wave 1988 & & \\
\hline
\end{tabular}

fall into the salaried worker category. Accordingly, a substantial fraction of immigrants are economically active after a return, with the majority in self-employment activities. ${ }^{3}$

The survey also reports three digit industry classifications for entrepreneurs. We have summarised this information, distinguishing between agriculture, trade, craft, and services. The numbers in Table 2 indicate that the highest percentage of entrepreneurs is active in the agricultural sector, followed by trading activities, services (which are mainly taxi or bus services, and restaurants), and the craft sector (which includes mechanics, carpenters, builders, etc.).

Most of these establishments are quite small, and many consist only of the selfemployed individual. In Table 3, we report the number of employees of the establishments. Nearly $40 \%$ of all establishments have no employees. The majority of firms are small in size, with between 1 and 5 employees (with a mean of 2.13).

It is likely that many employees in these firms are family members. One question in the survey asks for the type of employees in the establishment, distinguishing between family members and non-family members. In 131 establishments, family members are amongst the employees. In 77 establishments, individuals from outside the family are employed, with 65 of these establishments being in the size category 1 to 5. Firms which employ workers who are not family members are nearly exclusively non-agricultural enterprises (75 out of the 77).

Establishments of returned migrants are, according to these numbers, mostly small scale businesses, which may, nevertheless, be quite important as local employers. In our sample, $32 \%$ of all returning immigrants create jobs through entrepreneurial activity, and $12 \%$ of returning immigrants employ as entrepreneurs non-family members as workers.

As we discussed above, one reason for emigration of individuals who wish to become self-employed is limited access to credit markets in their home countries. There is evidence in our data which shows that in fact credit markets only play a minor role for returned migrants who become entrepreneurs. One question in the 1988 survey asks for the source of finance for the self-employment enterprise. The possible answers and the responses are displayed in Table 4, where responses are non-exclusive. Only $1.2 \%$ of those who are selfemployed report that bank credits were a major source of financing their enterprise. The

\footnotetext{
3 The relatively high percentage of self-employed individuals is in line with other studies on return migration. For instance, Gmelch (1980, p. 150) reports that in Ireland 30\% of returnee households had established small businesses.
} 
Table 3

Establishment size

\begin{tabular}{lccccc}
\hline & Works alone & $1-5$ employees & $6-10$ employees & $>10$ employees & Total \\
\hline Number & 127 & 181 & 11 & 4 & 323 \\
Percentage & 39.32 & 56.04 & 3.41 & 1.24 & 100.00 \\
Mean & - & 2.13 & 6.90 & 24.25 & - \\
& & & & & \\
Wave 1988 & & & & & \\
\hline
\end{tabular}

vast majority reports that the capital used to set up a business stems from savings, retirement funds, and return support.

The second largest group in our sample are individuals who retire from labour market activities after return. One may suspect that individuals in this group are close to, or above, retirement age. This, however, is not the case, as the numbers in Table 5 reveal. Although the average age of non-participants in 1984 is slightly higher than that of salaried workers and the self-employed, it is with 45.7 years (median 45 years) more than one and a half decades below retirement age. Only 6 of the 276 individuals in the non-employment group are older than 56 years in 1984, with the oldest being 60 years old.

In Table 5, we also report summary statistics on other characteristics of individuals in our sample, broken down according to their activity regime. The numbers in the table indicate some age differences between individuals in the three regimes. Individuals who do not participate are more than two years older at emigration than those who become selfemployed. Furthermore, the raw numbers in the table also suggest that those who choose the self-employment option have shorter migration durations than those who do not participate.

The level of schooling is coded from 1 to 9 ; individuals in category 1 have not attended school, but are able to read and write; individuals in categories 2 to 8 have increasing levels of school education, and individuals in category 9 have attended university. Category 0 are individuals who cannot read or write. The numbers in the table show some differences in educational achievements between the three groups. Entrepreneurs and salaried workers have higher levels of education than individuals who retire after return. We discuss the other variables in the table below.

The descriptions in this section illustrate that a substantial number of returned migrants chooses entrepreneurial activities, or retirement after return. Both options require the

Table 4

Financing of self-employment enterprise

\begin{tabular}{lrr}
\hline & Number & Percentage \\
\hline Savings in Germany & 214 & 63.88 \\
Return support, retirement contribution & 160 & 47.76 \\
Together with others & 29 & 8.66 \\
State support & 1 & 0.30 \\
Bank credit & 4 & 1.19 \\
Loans from friends & 10 & 2.99 \\
Sum & 418 & 124.8 \\
\hline
\end{tabular}

Notice: categories are non-exclusive. 
Table 5

Summary statistics

\begin{tabular}{|c|c|c|c|c|c|c|c|c|}
\hline \multirow[t]{2}{*}{ Description } & \multicolumn{2}{|c|}{ Non-participating } & \multicolumn{2}{|c|}{ Salaried worker } & \multicolumn{2}{|c|}{ Self-employed } & \multicolumn{2}{|l|}{ All } \\
\hline & Mean & S.D. & Mean & S.D. & Mean & S.D. & Mean & S.D. \\
\hline Years spent in Germany & 15.63 & 2.87 & 14.20 & 2.98 & 14.10 & 2.84 & 14.76 & 2.96 \\
\hline Age at entry & 29.99 & 4.37 & 26.90 & 4.06 & 27.57 & 4.33 & 28.56 & 4.50 \\
\hline Age in 1984 & 45.69 & 4.89 & 40.79 & 3.96 & 41.81 & 5.48 & 42.42 & 5.51 \\
\hline Married before emigration & 89.13 & - & 72.50 & - & 88.65 & - & 87.85 & - \\
\hline $\begin{array}{l}\text { No. of children before } \\
\text { emigration }\end{array}$ & 1.08 & 1.38 & 1.93 & 1.42 & 1.20 & 1.38 & 1.19 & 1.40 \\
\hline $\begin{array}{l}\text { Schooling before } \\
\text { emigration }\end{array}$ & 3.78 & 1.11 & 4.63 & 1.80 & 4.07 & 1.14 & 3.98 & 1.20 \\
\hline $\begin{array}{l}\text { Self-employed before } \\
\text { emigration }\end{array}$ & 24.63 & - & 17.50 & - & 45.39 & - & 34.73 & - \\
\hline Return was planned later & 35.50 & - & 50.00 & - & 38.34 & - & 37.85 & - \\
\hline No. & \multicolumn{2}{|c|}{276} & \multicolumn{2}{|c|}{40} & \multicolumn{2}{|c|}{330} & \multicolumn{2}{|c|}{646} \\
\hline
\end{tabular}

migrant to accumulate some capital in the host country. The accumulated capital stock upon return depends on the length of time the migrant spends abroad. In the next section, we formalise the process of activity choice, and the choice of the optimal migration duration.

\section{Migration duration and after-migration activity choice}

To investigate post-migration activities and the length of the migration period, we built the simplest possible model which allows us to study migration and re-migration decisions jointly with the future activity choice after an eventual return migration. In our model, the optimal migration duration and the planned future activity in the home country are simultaneously determined. In the case of an envisaged return, migrants decide between three activities in their home country: firstly, to live on their savings, and to refrain from any further labour market activity; secondly, to join the labour force as a salaried worker; and thirdly, to become self-employed. For each of the three regimes, the migrant determines the optimal consumption and migration duration. Comparing the utility levels under the three regimes (by evaluating the indirect utility functions), the migrant then chooses that regime which generates the highest utility.

In our model, time is continuous. Migrants are born at time 0 ; at time $\tau$, they are offered the option to emigrate. At time $T=1$, migrants die. In the case of an emigration, they may choose to return to the home country at time $t \in(\tau, 1]$. Migrants have perfect foresight of wages in the emigration- and immigration country, $w_{\mathrm{E}}$ and $w_{\mathrm{I}}$, which are constant over time. We assume that $w_{\mathrm{I}}>w_{\mathrm{E}}$ throughout the analysis. While being in the host country, the migrant supplies a constant input per unit of time to the labour market. The problem we consider here is the migrant's maximisation problem at time $\tau$.

The migrant maximises utility over the remaining life cycle $1-\tau$ by choosing the optimal levels of consumption $c_{\mathrm{E}}$ and $c_{\mathrm{I}}$ in home- and host country, the optimal return time 
$t$, and the activity he wishes to pursue after a return. For simplicity, there is no discounting in our model. The utility function is given by

$$
\begin{aligned}
U= & (1-t) \beta_{\mathrm{E}} \ln c_{\mathrm{E}}+(t-\tau) \beta_{\mathrm{I}} \ln c_{\mathrm{I}}-h_{\mathrm{s}}\left(\alpha_{\mathrm{s}}+(1-t) \beta_{\mathrm{s}}\right) \\
& -h_{\mathrm{w}}\left(\alpha_{\mathrm{w}}+(1-t) \beta_{\mathrm{w}}\right),
\end{aligned}
$$

where the three occupational choices after a return are described by the parameters $h_{\mathrm{s}}$ and $h_{\mathrm{w}}$, with

$$
\begin{array}{lll}
h_{\mathrm{s}}=1, & h_{\mathrm{w}}=0: & \text { Self-Employment, } \\
h_{\mathrm{s}}=0, & h_{\mathrm{w}}=1: & \text { Salaried Worker, } \\
h_{\mathrm{s}}=0, & h_{\mathrm{w}}=0: & \text { Non-Participation. }
\end{array}
$$

The first two terms in Eq. (1) represent utility from consumption flows $c_{\mathrm{E}}$ and $c_{\mathrm{I}}$ in emigration- and immigration country, respectively. We have chosen a simple logarithmic specification for the utility functions. The parameters $\beta_{\mathrm{E}}$ and $\beta_{\mathrm{I}}$ are preference parameters: we assume $\beta_{\mathrm{E}}>\beta_{\mathrm{I}} \geq 0$, i.e. the utility the migrant gains from the same flow of consumption is higher in the home- than in the host country. Reasons may be locational factors which produce externalities complementary to consumption, like climate, mentality, culture, etc. (see Djajic and Milbourne, 1988).

The two terms in the second line represent the disutility from activities as selfemployed or salaried worker after a return. They consist of two components: a fixed term $\left(\alpha_{\mathrm{s}} \geq 0\right.$ and $\left.\alpha_{\mathrm{w}} \geq 0\right)$, which may be considered as setup costs in the case of selfemployment, or search costs in the case of salaried employment, and variable costs $\beta_{\mathrm{s}} \geq 0$ and $\beta_{\mathrm{w}} \geq 0$, representing the disutilities from these two activities per unit of time.

The migrant maximises this utility function by choosing $c_{\mathrm{E}}, c_{\mathrm{I}}, t, h_{\mathrm{s}}$, and $h_{\mathrm{w}}$ subject to the following budget constraint:

$$
\begin{aligned}
\mathrm{BC}= & (1-t) c_{\mathrm{E}}+p(t-\tau) c_{\mathrm{I}}-(1-t) h_{\mathrm{w}} w_{\mathrm{E}} \\
& -(t-\tau)\left(1-h_{\mathrm{s}}\right) w_{\mathrm{I}}-r h_{\mathrm{s}} f(k, 1-t)=0,
\end{aligned}
$$

where $f(k, s)$ is the production function in the case he chooses self-employment. We assume $f$ to be linear in $k$ and $s$, where $k$ is the capital stock the migrant accumulates in the host country, and invests into self-employment activities, and $s$ is the length of time the migrant pursues self-employment activities after a return. We assume that the migrant invests his entire savings in setting up a business, and that he remains an entrepreneur for the remaining time in the home country. ${ }^{4}$ We can write $f$ as

$$
f(k, 1-t)=k(1-t)=\left(w_{\mathrm{I}}-p c_{\mathrm{I}}\right)(t-\tau)(1-t),
$$

where $\left(w_{\mathrm{I}}-p c_{\mathrm{I}}\right)(t-\tau)$ are savings the migrant accumulates while being abroad, and $(1-t)$ is the period of self-employment activity after a return.

\footnotetext{
4 This is optimal, as long as the production function has non-decreasing returns in the capital stock $k$, which we assume. With decreasing returns there may be an interior solution, and only a part of the accumulated capital stock is invested in entrepreneurial activities.
} 
Finally, $p$ is the price of goods in the host country, relative to the home country. We assume that $p>1$, i.e. the same bundle of goods is more expensive in the host country, and the migrant's purchasing power is higher at home. ${ }^{5}$

In our model, a return may occur for the following reasons: first, a relatively high preference for consumption at home, which in our model corresponds to $\beta_{\mathrm{E}}$ being large compared to $\beta_{\mathrm{I}}$. Secondly, a high purchasing power of the host country currency at home, which in our model can be expressed by a large value of $p$. In addition, our model introduces a third reason: a high return from self-employment activities at home, which can be expressed by a large value of $r$.

We concentrate our discussion on investigating the duration of migration, and the choice of activity after a return for the case that a return migration occurs. The conditions under which a migration, and a return migration occur are set out in Appendix A. The three different activities after a return imply a non-continuous budget constraint. The migrant maximises Eq. (1) subject to the budget constraint with respect to $t, c_{\mathrm{E}}$, and $c_{\mathrm{I}}$ for each of the three regimes. The optimal activity after return is found by comparing the indirect utilities in the three regimes obtained for the optimal choice of $t, c_{\mathrm{E}}$ and $c_{\mathrm{I}}$, and choosing the regime which is associated with the highest level of utility.

To illustrate the three choices and the resulting optimal durations graphically, we use numerical approximations, and display results in Fig. $1 .^{6}$ The left panel of Fig. 1 shows the utility frontiers when choosing self-employment (dashed line), work (bold line), and nonparticipation (thin line), where age at entry $(\tau)$ is on the horizontal line. The right panel displays the optimal return times for the three cases, where, again, the horizontal axis carries age at entry. The distance between the thin line and the solid line is the time the migrant spends at home after return.

For the chosen set of parameters, the migrant chooses self-employment if he enters the host country at a young age; he chooses to be a salaried worker if he enters the country at an intermediate age, and he chooses to retire if he enters the country at a late age. Since self-employment is only an option if the pay-off period for any investment undertaken is sufficiently long, this choice is not optimal if the worker emigrates late in life. Setup costs for self-employment activities can additionally reduce utility from self-employment. The unconditional means in Table 5 are roughly in line with these predictions. Those individuals who choose the self-employment option after return are about 2.5 years younger upon immigration than those who choose to retire.

The right panel of Fig. 1 displays the optimal migration durations for the three regimes. At the points of regime shifts, the optimal duration function is non-continuous. The figure illustrates that the duration-age entry profiles have different slopes for the different regimes. Suppose that the future activity in the home country is not known, and that we are interested in establishing the response of the optimal migration duration to differences in age at entry. The figure clearly illustrates that any data analysis, which does not

5 There are a number of reasons why this may be the case. Services are often considerably cheaper in emigration- than in immigration countries. Migrants' consumption choices may be restricted to particular goods, due to cultural or religious motives, which are not easily available in the host country. Recreational goods, like holidays in a sunny climate, may have to be bought in terms of expensive journeys.

${ }^{6}$ Parameter values for this example are $p=w_{\mathrm{I}}=4, w_{\mathrm{E}}=1, r=7 / 2, \alpha_{\mathrm{r}}=\alpha_{\mathrm{w}}=\alpha_{\mathrm{s}}=1 / 5, \beta_{\mathrm{w}}=\beta_{\mathrm{s}}=0, \beta_{\mathrm{E}}=3, \beta_{\mathrm{I}}=1$. 

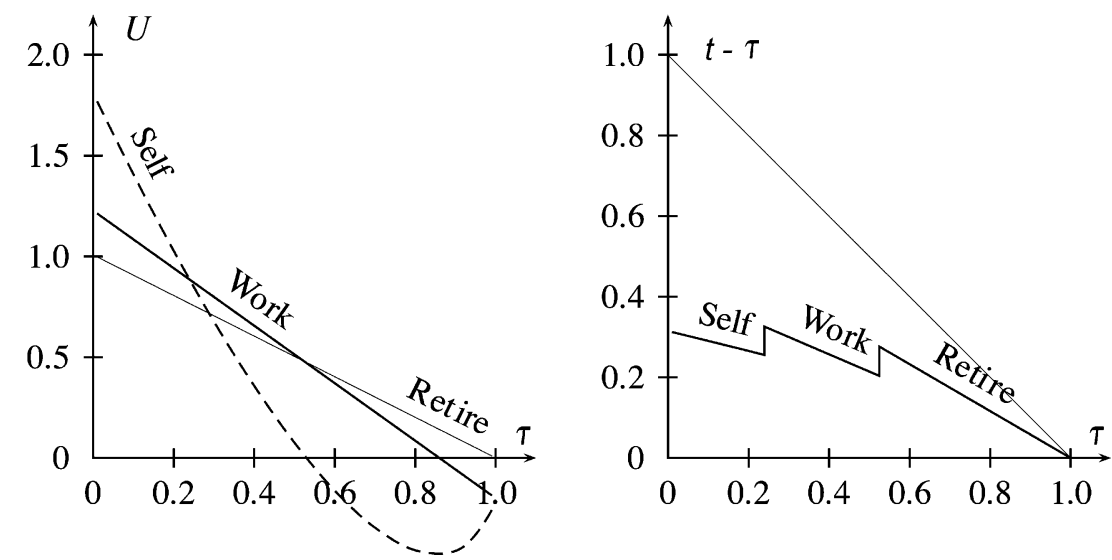

Fig. 1. Overall utility and duration in the host country.

distinguish between different activities after return, does not identify any of the three slopes. A similar argumentation holds for other variables, like wages. We come back to this point in the empirical section.

\subsection{Migration duration and activity choice after return}

We now investigate the comparative statics of the model with respect to the optimal migration duration in more detail. The non-continuity of the budget constraint makes the comparative statics less straightforward, since any change in a model parameter may induce a regime shift. We therefore distinguish between the effect of parameter changes on the duration within regimes.

Results are displayed in Table $6 .^{7}$ Economically important variables are wages in the host- and home country ( $w_{\mathrm{I}}$ and $w_{\mathrm{E}}$ ). Their effects on the optimal migration duration are interesting. Consider first an increase in wages in the emigration country (which decreases the wage differential). As indicated in the table, this decreases the optimal migration duration in the case of salaried employment after a return, which is the expected effect. Since this wage is irrelevant for the other two activities, it has no effect on the optimal migration duration in these regimes.

Now consider an increase in the host country wage. As the entries in the table indicate, the effect is ambiguous for the optimal migration duration for those who intend to become a salaried worker after a return. This ambiguity is generated by a classical substitution- and income effect: migrant workers would like to prolong their stay abroad as a direct response to higher wages - higher wages abroad allow a higher accumulation of wealth per unit of time abroad, and increase utility from consumption abroad. However, the marginal utility of wealth decreases if the host country wage increases. This reduces the gain from a further unit of time abroad, thus leading to a reduction of the optimal migration duration.

\footnotetext{
${ }^{7}$ In calculating these effects we assume the following: $\tau \in(0,1), w_{\mathrm{I}}>w_{\mathrm{E}}>0, p>1, r>0, \beta_{\mathrm{E}}>\beta_{\mathrm{I}}>0, \beta_{\mathrm{w}}>0$, $\beta_{\mathrm{s}}>0, \alpha_{\mathrm{w}}>0, \alpha_{\mathrm{s}}>0$. When calculating the effects we assume that $t$ and the regime are chosen optimally.
} 
Table 6

Comparative statics, optimal duration

\begin{tabular}{lccccccc}
\hline Parameters & $\tau$ & $p$ & $r$ & $w_{\mathrm{E}}$ & $w_{\mathrm{I}}$ & $\beta_{\mathrm{I}}$ & $\beta_{\mathrm{E}}$ \\
\hline Retired $\left(d(t-\tau)^{\mathrm{r}} / d \cdot\right)$ & - & - & 0 & 0 & - & \pm & \pm \\
Salaried $\left(d(t-\tau)^{\mathrm{w}} / d \cdot\right)$ & - & - & 0 & - & \pm & \pm & \pm \\
Self-employed $\left(d(t-\tau)^{\mathrm{s}} / d \cdot\right)$ & - & - & - & 0 & - & \pm & \pm \\
\hline
\end{tabular}

For the other two regimes, an increase in wages has an unambiguous and negative effect: the higher the wage abroad, the shorter the migration duration. Since in both regimes, the migrant does not enter the home country labour market after returning, staying abroad does not provide a relative gain in the accumulation of capital, thus eliminating the substitution effect. However, the second (the income) effect is still present: a higher wage abroad decreases the marginal utility of wealth, thus reducing the optimal migration duration. Furthermore, for the case of self-employment an early return allows to earn returns from accumulated capital for a longer period of time, generating an even stronger motive for an earlier return when wages in the host country increase.

These results are interesting, and suggest that increasing wages in the host country may lead to shorter migration durations. Moreover, this relationship is unambiguously negative if immigrants plan to refrain from further labour market activities upon return, and even stronger if they plan to become self-employed.

Other variables which affect the optimal migration duration are the entry age $\tau$, the preference parameters, the return to self-employment activities, and the purchasing power parameter $p$. The optimal duration $t-\tau$ always decreases if the worker enters the country at an older age. The return to self-employment activities has the expected effect on the duration in that regime. Increases in the purchasing power $p$ always decrease the optimal migration duration.

Finally, the preference parameters $\beta_{\mathrm{I}}$ and $\beta_{\mathrm{E}}$ have ambiguous signs for all the three regimes. Again, this is due to an income- and a substitution effect. Consider, for instance, the effect of $\beta_{\mathrm{I}}$. Higher preferences for consumption in the host country decrease, on the one side, consumption in the home country, thus reducing the optimal migration duration, since less resources are required for consumption at home. On the other side, an increase in $\beta_{\mathrm{I}}$ leads to a higher marginal utility of wealth, which increases the demand for wealth, and, accordingly, the optimal migration duration.

\section{Empirical analysis}

Our theoretical model has a number of interesting implications for empirical work. First of all, the way the optimal migration duration is related to regressors differs across regimes, suggesting that a common duration equation across regimes would impose invalid across-equation restrictions. Consider for instance the age at entry. It is well illustrated by Fig. 1 that the slope of the entry age-duration profiles differs across regimes. There is also a level effect, depending on which regime the individual has chosen. An increase in age at immigration therefore decreases the optimal migration duration within a regime, but may increase or decrease the optimal migration duration if it leads to a regime 
shift (for the parameterisation chosen for the figure, it increases the duration). Accordingly, straightforward estimation of the migration duration equation, without distinguishing between the three future activities, identifies only a combination of these two effects.

Furthermore, the model shows that optimal durations are determined simultaneously with the regime choice, and this should be taken into account at the stage of estimation. Finally, the comparative statics show that an increase in the host country wage does not necessarily increase the optimal migration length (as intuition may suggest). In fact, it may well decrease with the wage in the host country. The effect is unambiguously negative for the self-employment and the retirement regime, and ambiguous for salaried workers.

Our empirical model for the regime choice mimics the process of utility comparisons. We specify the regime choice as a comparison between the indirect utility functions. In this sense, we specify a reduced form model for the choice of regime, and estimate separate duration equations for each of the three regimes.

The choice of the regime is determined by a pairwise comparison of the indirect utilities for the three activities:

$$
\begin{aligned}
& U_{\mathrm{S}}>U_{\mathrm{W}}, \quad U_{\mathrm{S}}>U_{\mathrm{N}}: \quad \text { Self-Employment, } \\
& U_{\mathrm{W}}>U_{\mathrm{S}}, \quad U_{\mathrm{W}}>U_{\mathrm{N}}: \quad \text { Salaried Worker, } \\
& U_{\mathrm{N}}>U_{\mathrm{S}}, \quad U_{\mathrm{N}}>U_{\mathrm{W}}: \quad \text { Non-Participation, }
\end{aligned}
$$

where the indices $\mathrm{S}, \mathrm{W}$, and $\mathrm{N}$ indicate self-employment, salaried employment, and nonparticipation, respectively. This problem can be straightforwardly translated into a random utility maximisation problem by adding errors to the utilities:

$$
U_{i j}=Z_{i} \gamma_{j}+v_{i j}
$$

where $U_{i j}$ is the indirect utility of choice $j(j=\mathrm{N}, \mathrm{W}, \mathrm{S})$ for individual $i, Z_{i}$ is a vector of characteristics which affect the activity choice, and $\gamma_{j}$ is a vector of (regime-specific) parameters.

Assumptions about the $v_{i j}$ determine the nature of the model and the properties of its estimator. We assume that the errors $v_{i j}$ are type I extreme value distributed, which leads to the multinomial logit model. The probability of choosing alternative $j$ is given by (see Domenich and McFadden, 1975, for details)

$$
P_{i j}=F\left(Z_{i} \gamma_{j}\right)=\frac{\exp \left(Z_{i} \gamma_{j}\right)}{\sum_{k=\mathrm{S}, \mathrm{W}, \mathrm{N}}} \exp \left(Z_{i} \gamma_{k}\right) .
$$

Not all $\gamma_{j}$ are identified, and we normalise by setting $\gamma_{\mathrm{N}}=0$.

We are unlikely to observe all variables which determine the choices of immigrants. Unobservable characteristics of migrants which affect the regime choice may at the same time affect the optimal migration duration. Accordingly, conditional on observable characteristics, individuals in each regime may be non-randomly selected from the population of returning migrants. Our estimation strategy takes this into account by estimating the duration in each of the three regimes, and the regime choice equations simultaneously. 
The theoretical model suggests that the optimal migration duration depends on the age at entry, $\tau$, and wages in home- and host country, $w_{\mathrm{E}}$ and $w_{\mathrm{I}}$. It also depends on the preference parameters $\beta_{\mathrm{E}}$ and $\beta_{\mathrm{I}}$, and on the disutilities of working as salaried worker or as self-employed worker, $\beta_{\mathrm{s}}$ and $\beta_{\mathrm{w}}$. The optimal duration may be written as

$$
t_{\mathrm{R}}=t_{\mathrm{R}}\left(\tau, w_{\mathrm{I}}, w_{\mathrm{E}}, P r\right), \quad \mathrm{R}=\mathrm{N}, \mathrm{W}, \mathrm{S},
$$

where $\operatorname{Pr}$ summarises parameters which reflect preferences.

Our empirical specification is a linearised form of Eq. (8):

$$
t_{i j}=X_{i}^{\prime} \delta_{j}+e_{i j}, \quad j=\mathrm{N}, \mathrm{W}, \mathrm{S},
$$

where $t_{i j}$ is the duration of individual $i$ who has chosen regime $j$. The vector $X_{i}$ includes variables which affect the migration duration, and which we discuss below. Finally, $\delta_{j}$ is the respective parameter vector, and $e_{i j}$ is an error term.

We estimate Eqs. (7) and (9) simultaneously by maximum likelihood, thereby allowing the errors in selection- and duration equation to be correlated. ${ }^{8}$ We assume that the $e_{i j}$ are normally distributed. The $v_{i j}$ are extreme value distributed, and we use a transformation suggested by Lee (1982). Define $v_{i j}^{*}=\max \left(U_{i k}\right)-v_{i j}$, for $k \neq j$, and let

$$
u_{i j}=\Phi^{-1}\left(F\left(v_{i j}^{*}\right)\right)=J\left(v_{i j}^{*}\right),
$$

where $\Phi$ is the standard normal distribution. Accordingly, alternative $j$ is chosen if $u_{i j}<J\left(Z_{i j} \gamma_{j}\right)$, where, by construction, the variables $u_{i j}$ are standard normally distributed. We assume now that the pairs $\left(u_{i j}, e_{i j}\right)$ are bivariate normally distributed with zero mean vector and covariance matrix $\Sigma$. The log likelihood function is then given by

$$
\begin{aligned}
\ln L= & \sum_{\mathrm{N}} \ln \left[\phi_{\mathrm{N}}\left(e_{\mathrm{N}}\right) \int_{-\infty}^{J\left(Z \gamma_{\mathrm{N}}\right)} \phi_{u e_{\mathrm{N}}}\left(u \mid e_{\mathrm{N}}\right) \mathrm{d} e_{\mathrm{N}}\right] \\
& +\sum_{\mathrm{W}} \ln \left[\phi_{\mathrm{W}}\left(e_{\mathrm{W}}\right) \int_{-\infty}^{J\left(Z \gamma_{\mathrm{W}}\right)} \phi_{u e_{\mathrm{W}}}\left(u \mid e_{\mathrm{W}}\right) \mathrm{d} e_{\mathrm{W}}\right] \\
& +\sum_{\mathrm{S}} \ln \left[\phi_{\mathrm{S}}\left(e_{\mathrm{S}}\right) \int_{-\infty}^{J\left(Z \gamma_{\mathrm{S}}\right)} \phi_{u e_{\mathrm{S}}}\left(u \mid e_{\mathrm{S}}\right) \mathrm{d} e_{\mathrm{S}}\right]
\end{aligned}
$$

where the $\phi_{j}$ are standardised normal marginal density functions of $e_{j}$, and $\phi_{u e j}$ are standardised normal densities of $u$, conditional on $e_{j}$.

As regressors, only variables which are determined before the migrant's emigration qualify. Variables which are determined during or after the migration period may be affected by activity choice or/and duration, and they are endogenous in regime choice and duration equation. Our data set contains an array of characteristics before migration to the

\footnotetext{
${ }^{8}$ See Pradhan and van Soest (1995) for a similar model, applied to wage equations and participation choices in different sectors.
} 
host country. We include into $X_{i}$ the age at which the migrant enters the host country. We approximate the preference parameters by an indicator variable whether the migrant has been married before emigration, and by a measure for the number of children born before migration.

Unfortunately, we do not observe individual wages in the two countries. We observe however the level of education before emigration, which may reflect the relative productivity advantage of the better educated. If the return to the same level of schooling is higher in the host country, individuals with higher levels of schooling have a higher relative wage abroad. As a second measure for the immigrant's earnings abroad, we use his occupational class upon arrival to the host country. This variable should be positively related to his earnings potential.

The return aid programme may have led to distortions in the optimal migration duration. The financial rewards may have allowed migrants to return earlier than previously envisaged, thus leading to migration durations which are shorter than those compatible with optimising behaviour. To control for that, we use information based on a question in the first survey (1984). The migrant is asked whether a return had been planed at a later stage. On average, $38 \%$ of the migrants in our sample answer this question in the affirmative (see Table 5). We construct a dummy variable which is equal to one if the migrant responds that the return aid programme has reduced the previously envisaged migration duration, and include it among our regressors.

We include the same variables in $Z$ than in $X$. Our econometric model is parametrically identified by the distributional assumptions we impose on $e$ and $v$. For nonparametric identification, we need an exclusion restriction on the duration equation. To be a valid instrument, the excluded variable should affect the choice of activity after return, but the optimal migration duration only via the activity choice. We observe in our data whether an individual has been self-employed before emigration. Previous self-employment experience should reduce the fixed costs of becoming an entrepreneur. Former entrepreneurs are likely to be familiar with the bureaucratic processes involved, and with the initial obstructions and problems which go together with starting a business. Previous experience may also reduce the psychic costs involved in becoming self-employed.

Notice that this identification is also compatible with our theoretical model, where fixed costs are represented by the parameter $\alpha_{\mathrm{s}}$. Since $\alpha_{\mathrm{s}}$ enters the utility function additively, it does affect the activity choice after return, but not the optimal migration duration, except via the activity choice.

We have also estimated specifications which rely on parametric identification only; results are similar to those displayed below.

\section{Results}

In Table 7 we display the results for the duration of migration equation. All models are estimated by maximum likelihood. ${ }^{9}$ In the upper panel (models M1 and M2), we report

\footnotetext{
${ }^{9}$ All programs are written in GAUSS, and available on request from the authors.
} 
Table 7

Years of residence

\begin{tabular}{|c|c|c|c|c|c|c|c|c|}
\hline & \multirow{2}{*}{\multicolumn{2}{|c|}{$\frac{\text { All }}{\text { M1 }}$}} & \multicolumn{2}{|l|}{ No empl. } & \multicolumn{2}{|l|}{ Salaried } & \multicolumn{2}{|l|}{ Self } \\
\hline & & & & & \multicolumn{4}{|l|}{ M2 } \\
\hline & 1 & & 2 & & 3 & & 4 & \\
\hline & \multicolumn{8}{|c|}{ Single estimation } \\
\hline & Coeff. & $t$-ratio & Coeff. & $t$-ratio & Coeff. & $t$-ratio & Coeff. & $t$-ratio \\
\hline Constant & 17.245 & 17.045 & 21.682 & 13.954 & 19.767 & 5.932 & 15.039 & 10.811 \\
\hline Age at entry/10 & 0.226 & 0.749 & -1.121 & -2.528 & -1.177 & -1.008 & 0.724 & 1.648 \\
\hline $\begin{array}{l}\text { Schooling before } \\
\text { emigration } / 10\end{array}$ & -3.904 & -3.796 & -4.747 & -3.004 & -1.718 & -0.675 & -3.014 & -2.047 \\
\hline $\begin{array}{l}\text { Married before } \\
\text { emigration }\end{array}$ & -1.918 & -4.829 & -1.149 & -1.865 & -3.034 & -2.553 & -1.953 & -3.579 \\
\hline $\begin{array}{l}\text { No. children during } \\
\text { emigration }\end{array}$ & 0.117 & 1.442 & 0.051 & 0.454 & 0.463 & 1.203 & 0.118 & 1.021 \\
\hline $\begin{array}{l}\text { Return aid reduces } \\
\text { migration }\end{array}$ & -0.316 & -1.332 & 0.048 & 0.136 & 0.217 & 0.254 & -0.527 & -1.650 \\
\hline $\operatorname{Sigma}(u)$ & 2.870 & 35.665 & - & - & - & - & - & - \\
\hline $\operatorname{Sigma}\left(u_{N}\right)$ & - & - & 2.775 & 23.410 & - & - & - & - \\
\hline $\operatorname{Sigma}\left(u_{\mathrm{W}}\right)$ & - & - & - & - & 2.616 & 8.944 & - & - \\
\hline $\operatorname{Sigma}\left(u_{\mathrm{S}}\right)$ & - & - & - & - & - & - & 2.741 & 25.377 \\
\hline \multirow[t]{3}{*}{$\begin{array}{l}\text { Adj. } R^{2} \\
\text { Log-likelihood }\end{array}$} & \multicolumn{2}{|c|}{$\begin{aligned} & 0.05 \\
- & 2074.2\end{aligned}$} & \multicolumn{2}{|c|}{0.04} & \multicolumn{2}{|c|}{$\begin{array}{c}0.09 \\
-2046.54\end{array}$} & \multicolumn{2}{|c|}{0.05} \\
\hline & \multicolumn{4}{|l|}{ M3 } & \multicolumn{4}{|l|}{ M4 } \\
\hline & \multicolumn{4}{|c|}{ Simultaneous estimation } & & & & \\
\hline Constant & 16.677 & 14.748 & 12.728 & 6.226 & 23.830 & 4.599 & 15.090 & 10.381 \\
\hline Age at entry/10 & 0.206 & 0.685 & 1.220 & 2.070 & -1.078 & -0.885 & 1.360 & 2.780 \\
\hline $\begin{array}{l}\text { Schooling before } \\
\text { emigration } / 10\end{array}$ & -3.678 & -3.612 & -6.122 & -3.255 & -4.041 & -1.176 & -3.486 & -2.265 \\
\hline $\begin{array}{l}\text { Married before } \\
\text { emigration }\end{array}$ & -1.935 & -4.922 & -1.793 & -2.511 & -2.955 & -2.385 & -2.360 & -4.061 \\
\hline $\begin{array}{l}\text { No. children before } \\
\text { emigration }\end{array}$ & 0.126 & 1.549 & 0.062 & 0.454 & 0.711 & 1.547 & 0.078 & 0.648 \\
\hline $\begin{array}{l}\text { Return aid reduces } \\
\text { migration }\end{array}$ & -0.294 & -1.287 & -0.234 & -0.736 & 0.350 & 0.404 & -0.477 & -1.504 \\
\hline $\operatorname{Sigma}\left(u_{\mathrm{N}}\right)$ & 3.058 & 14.815 & 4.028 & 15.140 & - & - & - & - \\
\hline $\operatorname{Sigma}\left(u_{\mathrm{W}}\right)$ & 2.804 & 8.784 & - & - & 3.173 & 3.030 & - & - \\
\hline $\operatorname{Sigma}\left(u_{\mathrm{S}}\right)$ & 2.753 & 25.110 & - & - & - & - & 3.015 & 14.762 \\
\hline $\operatorname{Corr}\left(e_{\mathrm{N}} u_{\mathrm{N}}\right)$ & -0.548 & -1.877 & -0.932 & -2.541 & - & - & - & - \\
\hline $\operatorname{Corr}\left(e_{\mathrm{W}} u_{\mathrm{W}}\right)$ & 0.005 & 0.044 & - & - & 0.631 & 0.742 & - & - \\
\hline $\operatorname{Corr}\left(e_{\mathrm{S}} u_{\mathrm{S}}\right)$ & 0.055 & 0.228 & - & - & - & - & 0.560 & 2.380 \\
\hline
\end{tabular}

Log-likelihood

$-2051.06$

$-2037.66$

$\mathrm{M} 1: \operatorname{Corr}\left(e_{j} u_{j}\right)=0, j=\mathrm{N}, \mathrm{W}, \mathrm{S} ; \delta_{\mathrm{N}}=\delta_{\mathrm{W}}=\delta_{\mathrm{S}} ; \sigma_{\mathrm{N}}=\sigma_{\mathrm{W}}=\sigma_{\mathrm{S}}$.

$\mathrm{M} 2: \operatorname{Corr}\left(e_{j} u_{j}\right)=0, j=\mathrm{N}, \mathrm{W}, \mathrm{S}$.

M3: $\delta_{\mathrm{N}}=\delta_{\mathrm{W}}=\delta_{\mathrm{S}}$.

M4: No restrictions. 
results when estimating the duration equation and the regime choice equation independently, thus imposing zero-restrictions on the correlation coefficients between regime choice- and duration equation. In the lower panel (models M3 and M4), we allow for nonzero correlation coefficients. The first column (M1, M3) presents parameter estimates when we impose a common duration equation for the three regimes, and the last three pairs of columns (M2, M4) report results for regime-specific duration equations. Model M4 is the most general model, and nests all the other models.

\subsection{Specification tests}

We first compare the two specifications in the upper panel. Model M1 imposes the restriction that all parameters are equal across regimes, with a common variance. We allow for regime specific parameters in the duration equation, and regime specific variances in model M2 (columns 2-4). The number of restrictions imposed on specification M1 (compared to M2) is 14, and the difference in the likelihoods is 27.7. A likelihood ratio test rejects the restrictions at the 5\% level of significance, thus favouring the model which imposes no across-equation restrictions on the duration equations. This is in line with our theoretical model, which suggests that slope coefficients and intercepts of the duration profile differ across regimes.

In the lower panel, we report results of estimating regime choice equation and duration equation simultaneously. Again, the first pair of columns (M3) reports results where restrictions of equal parameters are imposed on the duration equation, but we allow for different variances in the three regimes, as well as for correlation between regime choice equation, and duration equation. This introduces considerable flexibility, since it allows for a different scaling of coefficients in the three regimes. Compared to model M4, the number of restrictions is 12 , and the difference in the likelihoods is 14 . Hence, the parameter restrictions on the duration equations cannot be rejected at the $5 \%$ level for this model. Again, model M1 is strongly rejected when comparing it to model M4.

Comparing the specifications which allow for correlation in the error terms with specifications which impose independence, we strongly reject the non-simultaneous models. ${ }^{10}$ The correlation coefficients indicate that unobservables which affect the nonemployment choice positively reduce migration durations, while unobservables which affect the salaried choice and the self-employment choice positively increase migration durations.

Based on these tests, we consider the simultaneous model, allowing for different parameters in the three duration equations (model M4), as most appropriate, and we focus the following discussion on this specification.

For models M1 and M2, we also report the (adjusted) coefficients of determination. They are quite small, indicating that there is quite a lot of unobserved heterogeneity

${ }^{10}$ The difference in likelihoods between the models in the first pair of columns in upper and lower panel is 23; the number of restrictions imposed is 5 (the three correlation coefficients, and the two variances). Since $\chi_{0.05}^{2}(5)=11.07$, the restrictions are rejected. For the models which allow for different parameters across regimes, the difference in likelihoods is 8.9 , and the critical value $\chi_{0.05}^{2}(3)=7.8$. 
unaccounted for by the model. We have also computed the pseudo- $R^{2}$ for the multinomial choice model, corresponding to models M1 and M2, which is $0.11 .^{11}$

\subsection{Migration duration}

As we discussed above, the level of schooling may capture higher relative wages of migrants in the host country: if the return to the same level of schooling is higher in the host country, individuals with higher levels of schooling have a higher relative wage abroad. According to our theoretical model, higher wages in the host country may decrease the optimal migration duration. Our coefficient estimates indicate that this variable decreases the optimal duration for individuals in all three regimes. The effects are strongly significant for the self-employed and the non-participants, and largest in size for the selfemployed. These results are compatible with the conjecture that higher host country wages decrease the optimal migration duration.

The level of schooling may however also capture other productivity advantages, like a higher return to self-employment activities in the home country. We therefore also estimate models where we introduce a further indicator for migrants' earnings abroad: the type of the first job received in Germany. Migrants were asked about the skill level required for their first job after entry to Germany, and responses were unskilled worker, semiskilled worker, and skilled worker. About $74.7 \%$ replied that their first job was an unskilled job, $8.5 \%$ replied that their first job was semiskilled, and 15.4\% replied that their first job was skilled. Conditional on educational achievements, this variable should reflect to some extent the average wage situation of the migrant in the host country. It is identified, conditional on education, if there is a random component about the allocation of new arrivers to good or bad jobs. This is likely, since the migrants we consider here had mostly been recruited and assigned to jobs while still residing in their home villages (see discussion above). First contracts were made with little information on the side of the migrant about the quality of the job.

We construct a dummy variable which assumes the value 1 if the individual reports to have obtained a qualified job in Germany as a first position, and add it as a regressor to $X$ and $Z$ in the most general model (M4). The coefficient on this variable is -0.66 for the self-employment equation, with a $t$-statistic of 1.55 . Thus, although not very precisely estimated, this estimate supports the hypothesis that those with higher wage opportunities abroad, and who intend to become self-employed after return, have a shorter duration in the host country. ${ }^{12}$

Estimates of the other coefficients are also interesting. The effect of the variable for the entry age on the optimal migration duration differs between the three regimes. Also, results from the independent estimation (M2) and the simultaneous estimation (M4) yield quite different coefficients for this variable. For the non-employment regime, this variable changes even sign. Since the unobserved error components between the selection equation and the duration equation are negatively (positively) correlated for the non-employment

11 The pseudo $R^{2}$ is defined as $1-L_{1} / L_{0}$, where $L_{0}$ corresponds to the log-likelihood of a constant only model, and $L_{1}$ is the log likelihood of the full model.

${ }^{12}$ For the non-employment regimes, the coefficient estimate is 0.116 , with $t$-statistic of 0.22 ; for the salaried regime, the estimate is -0.17 , with $t$-statistic of -0.16 . 
Table 8

Activity decisions, marginal effects (Model M4)

\begin{tabular}{|c|c|c|c|c|c|c|}
\hline & \multicolumn{2}{|c|}{ Non-employment } & \multicolumn{2}{|l|}{ Salaried } & \multicolumn{2}{|l|}{ Self } \\
\hline & Coeff. & $t$-ratio & Coeff. & $t$-ratio & Coeff. & $t$-ratio \\
\hline Constant & -0.453 & 2.445 & -0.105 & 1.456 & 0.558 & 2.932 \\
\hline Age at entry/10 & 0.316 & 5.804 & 0.001 & 0.038 & -0.317 & 5.541 \\
\hline Schooling before emigration $/ 10$ & -0.588 & 3.008 & 0.117 & 1.779 & 0.470 & 2.364 \\
\hline Married before emigration & -0.147 & 2.041 & -0.014 & 0.637 & 0.161 & 2.236 \\
\hline No. children before emigration & -0.006 & 0.429 & -0.012 & 1.861 & 0.018 & 1.291 \\
\hline Self-employed before emigration & -0.188 & 5.060 & -0.044 & 2.281 & 0.233 & 6.233 \\
\hline
\end{tabular}

(self-employment) regime, and the effect of entry age on the regime choice is positive for the non-employment regime, and negative for the self-employment regime (see Table 8), non-simultaneous estimation leads to a downward bias of the age at entry variable for both regimes.

In the simultaneous model, the age at entry coefficients indicate that a higher entry age leads to a longer migration duration in the self-employment and the non-employment regime. This seems to be in contradiction to our theoretical model. One explanation for these results is that entry age may capture some components which we have not explicitly considered in our model. Workers who are older at entry may find it more difficult to adjust to the labour market conditions in the host country, which may prolong the time period necessary for accumulating enough capital.

The remaining variables reflect the preference of the immigrant for the home country. Being married before emigration decreases strongly the optimal migration duration in all three regimes. Individuals who were married before emigration are likely to have, and to maintain stronger links to the home country. Living as a couple in a foreign country allows to preserve habits, and imposes a restraint on integration. In terms of our theoretical model, married individuals may have a higher marginal utility from consuming at home. The number of children before migration has a positive, but not significant effect on the optimal migration duration. There are two ways in which this variable may influence the optimal migration duration: firstly, by increasing the migrant's preference for his home country; secondly, by allocating more resources to consumption, implying a longer period necessary to accumulate savings.

\subsection{Regime choice}

We now turn to the regime choice equation. We only discuss coefficient estimates of specification M4, which are displayed in Table 8. Results for the other specifications are similar. The activity choice equation we estimate is a reduced form equation, and reflects the comparisons of indirect utilities across regimes. Table 8 presents the estimates. We display in the table marginal effects, evaluated at sample means. ${ }^{13}$

\footnotetext{
${ }^{13}$ Marginal effects are computed as $\delta P_{j} / \delta x_{i}=P_{j}\left(\gamma_{j}-\sum_{k=1}^{3} P_{k} \gamma_{k}\right)$. Standard errors are computed by simulations; we draw 500 samples from the asymptotic normal distribution of the parameter estimates, and compute the means.
} 
Age at entry appears to be a strong predictor for the choice of activity. An increase in entry age by 1 year is associated with a $3 \%$ increase in the probability of being nonemployed, and with a similar percentage decrease in the probability of being selfemployed. The effect on the probability to choose the salaried worker option is basically zero. The relative magnitude of these effects are in line with the predictions of our theoretical model above. If workers emigrate at a late stage of their life, the selfemployment choice is not optimal, since setup costs reduce utility from entrepreneurship, relative to non-employment.

The level of schooling increases the probability to choose the self-employment or the salaried worker option, and decreases the probability of non-participation. Individuals with higher levels of education may expect a higher wage in the home country, which could be a reason for the positive effect on the salaried worker option; also, education may positively affect the return to self-employment activities, and therefore increase the probability of choosing this option.

The variables which reflect the disutilities of living abroad include whether the individual has been married before emigration, and the number of children the migrant had before emigration. The children variable is not significant. Being married before emigration however decreases the probability to be non-employed, and increases the probability to become self-employed. As expected, being self-employed before emigration is a strong predictor for the probability to be self-employed after return, and decreases the probability to choose the salaried and non-employment option.

\section{Summary and conclusions}

In this paper, we analyse the choice of activity of returned migrants in their home countries, and the length of their migration abroad. Based on survey data of returned migrants to Turkey, we illustrate that most returnees choose self-employment or nonemployment as after-return activity.

We develop a simple model which allows us to study the optimal migration duration of migrants, together with their choice of activity after returning home. We establish the conditions for a return migration to take place, and derive the comparative statics for the optimal migration duration. Our model illustrates that the effect of variables on the optimal migration duration differs according to the activity regime chosen after return. Furthermore, our model predicts that an increase in host country wages may decrease migration durations in all three regimes.

Our analysis emphasises the need to model migration durations jointly with after-return activity choices. We specify and estimate an empirical model, which is compatible with our theoretical framework, and where migrants choose the activity regime after a return in conjunction with the optimal migration duration. We draw on a unique survey data set of immigrants who returned to their home country, and who were subsequently interviewed. Results of our empirical analysis are largely in line with our theoretical predictions. We reject the restrictions of imposing the same coefficients across regimes on variables explaining the optimal migration duration. We also reject models which do not allow for a correlation in the error terms in duration- and regime choice equation. We find that the 
level of schooling decreases the length of the migration period. If the better educated receive higher relative wages abroad, then education should reflect a high relative wage abroad, which, according to our theoretical model, may lead to a decrease in the migration duration. Results of some additional tests, which use occupational class upon arrival as a further proxy for wages abroad, are also compatible with the hypothesis that higher wages abroad lead to shorter migration durations for the self-employed. Finally, we find that family bounds established before emigration reduce the optimal migration duration in all three regimes.

As for the after-return activity choice, we find that an increase in the age at entry reduces the probability that an individual chooses the self-employment or salaried worker option, relative to the non-employment option. Finally, our results indicate also that better educated individuals are more likely to be active after returning home.

\section{Acknowledgements}

We are grateful to Ian Preston for helpful suggestions. Many thanks to Elmar Hönekopp for making the data available to us.

\section{Appendix A}

In the theoretical model that we study in this paper we consider the case of a worker who emigrates to a foreign country and who returns after some years. This, of course, is not necessarily optimal. It might be better never to migrate, or never to return. In the following section we establish conditions for an interior solution.

We do this for the three regimes separately. We always consider a worker who emigrates at time $\tau$ and has to return at time $t$ in order to choose activity $A \in\{\mathrm{R}, \mathrm{W}, \mathrm{S}\}$. This worker chooses $c_{\mathrm{E}}$ and $c_{\mathrm{I}}$ optimally to maximise his utility given the budget constraint. Denote the indirect utility $\hat{U}(\tau, t, A)$.

The marginal utility of the first unit of time in the host country is given by $\left.d_{t} \hat{U}_{A}\right|_{t \rightarrow \tau}$. If this expression is negative, the migrant will not migrate; if it is positive, the migrant will migrate.

The marginal utility of spending the last moment in the workers life in the host country is $\left.d_{t} \hat{U}_{A}\right|_{t \rightarrow 1}$. The worker remains permanently in the host country if this expression is still positive, he returns if this expression is negative. ${ }^{14}$

Let us first consider the self-employment regime (S). It is easy to see that the worker will always migrate and always return. If he would not migrate, he is left without capital for his business, which means that $U=-\infty$. The first marginal unit of time spent in the host country increases his utility by an infinitely large amount. This worker will also always return, because otherwise $U=-\infty$ in the last marginal moment of his life. ${ }^{15}$

\footnotetext{
${ }^{14}$ Notice that it is not obvious that migration and return decision can be reduced to studying these limits. However, under the above assumptions utility over time $\hat{U}$ is sufficiently monotonic to allow this simplification.

${ }^{15}$ Given that in the limit $t \rightarrow 1$, the amount of time spent at home $(1-t)$ decreases only linearly, while utility decreases exponentially. Therefore, the overall limit is $U=-\infty$.
} 
Next consider the case of the worker who is retiring after his return (R). Also under this regime the worker will always migrate since the first marginal unit of time spent in the host country increases his utility by an infinitely large amount. However, this worker will only return if $\left.d_{t} \hat{U}_{\mathrm{R}}\right|_{t \rightarrow 1}<0$ where $\left.d_{t} \hat{U}_{\mathrm{R}}\right|_{t \rightarrow 1}$ can be expressed as follows:

$$
\left.d_{t} \hat{U}_{\mathrm{R}}\right|_{t \rightarrow 1}=\underbrace{\beta_{\mathrm{E}}\left(1-\ln \frac{w_{\mathrm{I}} \beta_{\mathrm{E}}}{\beta_{\mathrm{I}}}\right)}_{\begin{array}{c}
\text { foregone marginal utility of } \\
\text { consumption at home }
\end{array}}+\underbrace{\beta_{\mathrm{I}} \ln \frac{w_{\mathrm{I}}}{p}}_{\begin{array}{c}
\text { marginal } \\
\text { in thility of consumption }
\end{array}} .
$$

In the case of salaried employment (W), neither migration nor return can be taken for granted. We find that

$$
\left.d_{t} \hat{U}_{\mathrm{W}}\right|_{t \rightarrow \tau}=\underbrace{\beta_{\mathrm{I}}\left(-1+\ln \frac{w_{\mathrm{E}} \beta_{\mathrm{I}}}{p \beta_{\mathrm{E}}}\right)}_{\begin{array}{c}
\text { marginal utility of } \\
\text { consumption abroad }
\end{array}}+\beta_{\mathrm{E}}(\underbrace{\frac{w_{\mathrm{I}}}{w_{\mathrm{E}}}}_{\begin{array}{c}
\text { wage substitution } \\
\text { effect }
\end{array}}-\underbrace{\ln w_{\mathrm{E}}}_{\begin{array}{c}
\text { foregone marginal } \\
\text { utility of consumption } \\
\text { at home }
\end{array}})+\underbrace{\beta_{\mathrm{W}}}_{\begin{array}{c}
\text { marginal } \\
\text { disutility } \\
\text { of work }
\end{array}},
$$

and

$$
\left.d_{t} \hat{U}_{\mathrm{W}}\right|_{t \rightarrow 1}=\left.d_{t} \hat{U}_{\mathrm{R}}\right|_{t \rightarrow 1}-\underbrace{\beta_{\mathrm{I}} \frac{w_{\mathrm{E}}}{w_{\mathrm{I}}}}_{\text {wage substitution effect }}+\underbrace{\beta_{\mathrm{W}}}_{\text {marginal disutility of work }} .
$$

We have an interior solution for all regimes if the following holds:

$$
\left.d_{t} \hat{U}_{\mathrm{R}}\right|_{t \rightarrow 1}<\left.0 \wedge d_{t} \hat{U}_{\mathrm{W}}\right|_{t \rightarrow \tau}>\left.0 \wedge d_{t} \hat{U}_{\mathrm{W}}\right|_{t \rightarrow 1}<0
$$

It is easy to see that, given the restrictions imposed above, one can, for any combination of $p, w_{\mathrm{E}}, w_{\mathrm{I}}, \beta_{\mathrm{E}}, \beta_{\mathrm{W}}$, always find a $\bar{\beta}_{\mathrm{I}}>0$ such that all $\beta_{\mathrm{I}} \in\left[0, \bar{\beta}_{\mathrm{I}}\right]$ fulfill the three inequalities.

\section{References}

Borjas, G.J., 1987. Self-selection and the earnings of immigrants. American Economic Review 77, $531-553$.

Borjas, G.J., 1994. The economics of immigration. Journal of Economics Literature 32, 1667-1717.

Chiswick, B.C., 1978. The effect of americanization on the earnings of foreign-born men. Journal of Political Economy 86, 897-921.

Djajic, S., Milbourne, R., 1988. A general equilibrium model of guest-worker migration: a source-country perspective. Journal of International Economics 25, 335-351.

Domenich, T., McFadden, D., 1975. Urban Travel Demand: A Behavioral Analysis. North Holland, Amsterdam.

Dustmann, C., 1995. Savings behaviour of temporary migrants - a life cycle analysis. Zeitschrift fuer Wirtschafts-und Socialwissenschaften 4, 511-533.

Dustmann, C., 1997. Return migration, savings and uncertainty. Journal of Development Economics 52, 295 -316.

Dustmann, C., 2001. Return migration, wage differentials, and the optimal migration duration. forthcoming European Economic Review, IZA discussion paper No. 264. 
Funkhouser, E., 1992. Remittances from international migration: a comparison of El Salvador and Nicaragua. Review of Economics and Statistics 77, 137-146.

Galor, O., Stark, O., 1991. The probability of return migration, migrants' work effort, and migrants' performance. Journal of Development Economics 35, 399-405.

Gmelch, G., 1980. Return migration. Annual Review of Anthropology 20, 127-144.

Hiemenz, U., Schatz, K.W., 1979. Trade in place of migration: an unemployment oriented study with special reference to the Federal Republic of Germany, Spain, and Turkey. International Labour Organisation, Geneva.

Hönekopp, E., 1987. Rückkehrförderung und Rückkehr ausldndischer Arbeitnehmer. Beiträge zur Arbeitsmarktund Berufsforschung 114, 287-366.

Lee, L.F., 1982. Some approaches to the correction of selectivity bias. Review of Economic Studies 49, 355-372.

Lucas, R., Stark, O., 1985. Motivations to remit: evidence from Botswana. Journal of Political Economy 93, 901-916.

Mehrldnder, U., 1980. The 'human resource' problem in Europe: migrant labor in the FRG. In: Raaman, U. (Ed.), Ethnic Resurgence in Modern Democratic States. Pergamon, New York, pp. 77-100.

Mesnard, A., 2000. Temporary migration and capital market imperfections, mimeo, University of Toulouse. June 2000.

Pradhan, N., van Soest, A., 1995. Formal and informal sector employment in urban areas in Bolivia. Labour Economics 2, 275-298.

Robinson, V., 1986. Bridging the Gulf: the economic significance of South Asian migration to and from the Middle East. In: King, R. (Ed.), Return Migration and Regional Economic Problems. Croom Helm, London.

Stark, O., Helmenstein, C., Yegorov, Y., 1997. Migrants saving, purchasing power parity, and the optimal duration of migration. International Tax and Public Finance 4, 307-324. 